LA PRESENCIA DE LA METAFÍSICA FICHTEANA EN

ESTEBAN ECHEVERRÍA Y JOSÉ MÁRMOL

Continuidades en torno a la figura del peregrino

Lucas Scarfia 


\section{Lucas Scarfia}

Universidad de Buenos Aires

\section{La presencia de la metafísica fichteana en Esteban Echeverría y José} Mármol. Continuidades en torno a la figura del peregrino

DOI: $10.36446 /$ be. 2020.53 .226

\section{Resumen}

El presente trabajo plantea como hipótesis que la fuente de influencia más profunda en el pensamiento romántico argentino no fue el romanticismo francés sino el idealismo y el romanticismo alemán. Se trata de demostrar el influjo de la metafísica del anhelo, que Fichte expone en la Grundlage der gesamten Wissenschaftslehre (1794-1795), en dos obras: El peregrinaje de Gualpo (ca. 1825) de Esteban Echeverría y los Cantos del peregrino (1846) de José Mármol. De esta manera se muestra el modo en que uno y otro de los autores caracterizan la figura del peregrino como personaje principal y alter ego en sus textos. A su vez, se resaltan las nociones de melancolía y de hastío como enclaves que conforman el pensamiento idealista y romántico. En este sentido se muestra que tanto Fichte como los Frühromantiker y los intelectuales argentinos, forman parte de una corriente de pensamiento idealista y romántico que cabe calificar como melancólico, práctico y moral.

\section{Palabras clave}

Finito; Infinito; Subjetividad; Unidad; Melancolía

\section{The presence of Fichtean metaphysics in Esteban Echeverría and José}

\section{Mármol. Continuities around the figure of the pilgrim}

\section{Abstract}

This paper states as hypothesis that the deepest source of influence in Argentinean romantic thinking was not the French Romanticism but German Idealism and Romanticism. The main objective is to present the impact of the metaphysics of longing that Fichte exposes in Grundlage der gesamten Wissenschaftslehre (1794-1795), in two works: Esteban Echeverría's El peregrinaje de Gualpo (ca. 1825) and José Mármol's Cantos del peregrino (1846). In this manner it is displayed the way in which both authors characterize the figure of the pilgrim as main character and alter ego in their writings. Also, the notions of melancholy and tedium are highlighted as key points that configure idealistic and romantic thought. In this sense it is demonstrate that Fichte as the Frühromantiker and Argentinean intellectuals participate of an idealistic and romantic current of thought that must be classified as: melancholic, practical and moral.

\section{Keywords}

Finite; Infinity; Subjectivity; Unity; Melancholy

Recibido: 13/08/20. Aprobado: 26/10/20.
"[A]nhelo»; un impulso hacia algo [...] desconocido, que sólo se manifiesta por una «necesidad», por un «malestar», por un «vacío» que intenta llenarse y que no indica a partir de qué.

El yo siente en sí un anhelo; él se siente menesteroso.

Fichte, GA I/2: 431

¿Qué corazón es el mío? [...] / ¿Cómo cabe entre mi pecho, cuando su vuelo atrevido halla el universo estrecho, desprecia lo conseguido, / y sin cesar pide más? / ¿Cómo [...] anhela / se roe a sí mismo, y vela / sin fatigarse jamás?

Echeverría, OCEC III: 171-172

[E]se Carlos, insondable foco de perpetua inquietud y de constancia [...] / se recrea en desechar la idea / que antes buscaba el corazón con ansia: / alma que vive en perdurable hastío [...] /

y cuando está en su mano / la posesión de a lo que inquieto aspira, / por algo más lejano / su veleidoso corazón suspira.

Mármol, Cantos del peregrino - Canto segundo

Al estudiar la génesis y el desarrollo del pensamiento romántico de los intelectuales argentinos de la primera mitad del siglo XIX, se observa que la mayoría de la bibliografía crítica estableció un vínculo indisoluble entre aquel y el romanticismo francés de pensadores como Constant, Lamartine, Chateaubriand, Hugo y Musset. ${ }^{1}$ En continuidad con ello, esta perspectiva de investigación no puso el foco en la relación conceptual entre los argentinos y los primeros

${ }^{1}$ Para un ejemplo resonante de este caso véase Sarlo 1997: 17 ss. Por otra parte, cabe mencionar a nivel de Proyectos de Investigación acreditados e institucionalizados en el país acerca del tema de este artículo, el Proyecto PICT 2016-0204 "Historia de las Ideas estéticas en Argentina", a cargo del editor del Boletín de Estética-como un antecedente académico saliente en la materia.

Boletín de Estética 53: 39-75, 2020

ISSN 2408-4417 (online) | DOI: 10.36446/be.2020.53.226 
románticos alemanes (Frühromantiker), como tampoco respecto de los filósofos del idealismo alemán: Fichte, Schelling y Hegel.

Empero cabe decir que la influencia de los románticos franceses no modificó ni mucho menos eliminó -y por lo tanto no se debería dejar de lado-, el poder que tuvo la filosofía idealista y romántica alemana sobre las ideas de aquellos intelectuales. Sin embargo, Myers afirma:

la filosofía alemana [...] denominada [...] 'romántica', cuyos mayores representantes eran Fichte, Schelling y Hegel, no tuvo ninguna presencia real en el pensamiento de la Nueva Generación Argentina, como tampoco la tuv[o] la filología [...] de los hermanos Schlegel [...]. [T] ampoco [...] tendrían cabida las exploraciones de la locura de un Novalis [...]. (Myers 2005: 418-419)

El extendido alcance de este punto de vista conlleva la necesidad de desarrollar un estudio de la conexión entre idealistas y románticos alemanes respecto de los argentinos, en pos de señalar una perspectiva exegética que, sin encontrarse aislada de otros puntos de vista, promueva una reflexión más abarcativa y profunda en torno a la cuestión. Por otra parte, si bien este trabajo propone una lectura distinta a la que expone la cita, cabe decir que en aquel análisis hay algo de sensatez. En efecto, intelectuales como Echeverría, Sarmiento, Alberdi y Gutiérrez, tuvieron contacto directo con las obras de los franceses al pisar el suelo de su patria. Así su ascendencia sobre ellos resulta remarcable. ${ }^{2}$

2 También cabe señalar la relación de los autores argentinos con el romanticismo inglés -en concreto con Lord Byron. Echeverría da cuenta de su interés por el poeta en diversos pasajes de sus escritos (véase Echeverría, OCEC V: 153-154). En particular cabe resaltar la influencia de Childe Harold's Pilgrimage (1812-1818) en la conformación del peregrino como personaje principal de las obras de Echeverría y de Mármol. También Arrieta (1953: XXXV) traza el paralelo entre estos textos
Si se toma en cuenta la vida de Echeverría, hay que destacar que permaneció en Francia durante cuatro años, desde marzo de 1826 a mayo de 1830. De este modo, y a partir del manejo de su lengua -lo cual no tenía equivalencia respecto de la lengua alemana-, tuvo un amplio acceso a obras de pensadores franceses. Así pues, cabe subrayar la apropiación que realizó de cómo estos últimos utilizaron los conceptos de melancolía y de hastío, así como del sentido de paisajes naturales como el mar y el desierto en tanto imágenes que remiten al anhelo de lo infinito. También es importante destacar aquí que los románticos argentinos reapropiaron el concepto francés de $\mathrm{mal} d u$ siècle, para dar cuenta de la estructura metafísica e histórica de la subjetividad romántica. ${ }^{3}$

Dicho esto, es innegable la influencia del romanticismo francés en Echeverría y también en el resto de los románticos argentinos. En efecto, el presente artículo no propone refutar este punto. Pero sí es vital señalar que, también en París, Echeverría tuvo acceso al espíritu romántico alemán que importó Madame de Staël. Ella introdujo en Francia, luego de su estancia en Alemania entre finales de 1803 y 1804 , los temas y las ideas en boga de los idealistas y románticos de este país. ${ }^{4}$ Esto cobró forma en la redacción e impresión del texto: $D e$

siguiendo al propio Mármol. Los textos echeverrianos se citan a partir de la edición de sus obras completas que realizó Gutiérrez entre 1870 y 1874 [OCEC].

${ }^{3}$ Aquí cabe remitir al relevamiento que hace Hoog (1954: 42-48), acerca de la historia de este concepto a lo largo de la literatura romántica francesa del siglo XIX.

${ }^{4}$ Echeverría resalta esta cuestión en su texto Clasicismo y romanticismo (1837/1838, publicado de manera póstuma en 1873) (véase Echeverría, OCEC V: 98). También Jitrik (1979: 244) y Ortiz (2007: 137) destacan cómo el romanticismo alemán llega a Francia por esta mediación. Por último, Lotufo (2017: 164) expone la apropiación que hizo Staël respecto del rol que los románticos alemanes adjudicaron al concepto de naturaleza. Por su parte Echeverría remite a los hermanos Schlegel en distintos textos. En Fondo y forma de las obras de la imaginación (1837/1838, publicado de manera póstuma en 1873) nombra a August Wilhelm (véase Echeverría, OCEC V: 
l'Allemagne (1810) -aunque la policía imperial confiscó la obra y sólo se publicó en 1813-1814 tras la caída de Napoleón.

En este escrito, Staël da cuenta de la filosofía, la literatura y la poética alemana desde Goethe y Schiller a Jacobi, Herder, Kant y Fichte, así como a los hermanos Schlegel, Tieck y Novalis. El espíritu intelectual $\mathrm{y}$, en algunos casos, romántico de los alemanes era -de acuerdo con las palabras de Staël-, extraño para la intelectualidad francesa de la época. ${ }^{5}$ Así pues la autora se esfuerza por exponer y resaltar el valor de sus ideas. En particular respecto de los Frühromantiker, destaca su capacidad para poner en conjunción las facultades de la imaginación y la razón, ${ }^{6}$ así como -en concreto en cuanto a Novalis-, su talento para favorecer una nueva comprensión de la relación entre el sujeto y la naturaleza. ${ }^{7}$

En continuidad con los señalamientos anteriores, y pese a las limitaciones idiomáticas y geográficas, no es extraño que la influencia del romanticismo francés en Echeverría y en Mármol reporte, en paralelo, el tono del pensamiento alemán que Staël se ocupó por dar a conocer. En esta línea de lectura, Krumpel destaca:

muestra de un acontecimiento importante para la recepción latinoamericana [del romanticismo], es la estancia de Esteban Echeverría en el Salón de París. En 1830 Echeverría retornó a Argentina. Mediante él se conocieron en el campo cultural latinoamericano las posiciones histórico-filosóficas de los primeros románticos alemanes -Herder, los hermanos Schlegel y Novalis. Alberdi escribió que él recibió las primeras noticias

77). Y en la Advertencia a las Rimas (1837) cita al menor de ellos (véase Echeverría, OCEC V, 148).

${ }^{5}$ Véase Staël [1810] (1852: 11).

${ }^{6}$ Véase Staël [1810] (1852: 366).

7 Véase Staël [1810] (1852: 566-568). sobre el romanticismo alemán a partir de Echeverría. Desde entonces se expandió el punto de vista según el cual el romanticismo era un movimiento espiritual de profunda raíz germana que contribuyó de modo esencial a la renovación de la cultura francesa. En conexión inextricable con ello también arribaron las ideas de Kant, Fichte, Schelling y Hegel a Latinoamérica. (Krumpel 1999: 119) ${ }^{8}$

De esta manera cabe dar cuenta de forma explícita de la hipótesis que guía el trabajo, a saber: que las obras poéticas de los románticos argentinos están atravesadas -además de por el romanticismo francés, o más aun, mediante esta misma vía-, por el pensamiento idealista y romántico alemán. Se trata en particular de la presencia de la metafísica del anhelo o ansia [Sehnen], como dinámica que estructura la subjetividad en sentido práctico -según la expone Fichte en la tercera parte de la primera versión de su sistema filosófico, es decir: Grundlage der gesamten Wissenschaftslehre (GWL) (1794-1795).

De acuerdo con esta doctrina, el sujeto se encuentra siempre en un movimiento de búsqueda de unidad consigo mismo y de determinación recíproca [Wechselbestimmung] con respecto al mundo. En otras palabras, esta clase de idealismo -y también del Primer

\footnotetext{
${ }^{8}$ La traducción es propia. A su vez Poviña (1955: 575) remite al conocimiento de Echeverría respecto de Kant y de Fichte, a partir de su referencia en el escrito Revolución de febrero en Francia (1848). Aquel autor califica este texto como el trabajo echeverriano de mayor importancia a nivel filosófico. Es importante anticipar que allí Echeverría sostiene que Kant y Fichte contribuyeron a la elaboración de la teoría de la perpetua perfectibilidad del hombre. Esta tesis cobra valor en tanto se la piense en continuidad con el sentido práctico-moral con el que, en este trabajo, se muestra el idealismo fichteano y romántico tanto alemán como argentino -en particular a partir del concepto de anhelo. Por otro lado cabe remitir a la lectura que realiza Suárez Urtubey (1987: 67), quien también destaca la fuerte impronta que marcó en Echeverría el romanticismo alemán -en particular a través de la mediación del romanticismo francés.
} 
romanticismo alemán (Frühromantik) que, en ciertos casos y puntos en particular, se desprende de él- sostiene que es imposible absolutizar y unificar los aspectos finito e infinito de la subjetividad.

De esta manera cabe resaltar el carácter moral de la filosofía fichteana. En tanto Fichte no concibe la posibilidad de aquella unidad metafísica, concluye que el sentido primordial de la existencia subjetiva es un sentido práctico. Es decir que el sujeto no puede más que, a través del anhelo de lo infinito, desarrollar su vida en pos de la transformación -o en términos novalianos, romantización-, ${ }^{9}$ de lo finito en infinito en un proceso por siempre inacabado.

La dinámica del anhelo y de la actividad moral encarna en los personajes de El peregrinaje de Gualpo ( $P G$ ) (editado por primera vez en 1873 pero que Gutiérrez fecha en 1825) y en los Cantos del peregrino (CP) (1846) de Echeverría y de Mármol, respectivamente. Por su parte, también hay que anticipar en este punto la asociación entre el concepto fichteano de Sehnen y los conceptos románticos de melancolía [Sehnsucht, Wehmut] y de hastío [Langeweile]. Los personajes románticos de las obras de Echeverría y de Mármol son descritos como sujetos hastiados y melancólicos en continua añoranza de un mundo ideal que no se puede presentar en la realidad.

Ahora bien, contra una común opinión en torno a la descripción de la subjetividad romántica como melancólica, no hay que concluir que la imposibilidad del cumplimiento del anhelo implica el cese de la actividad de este sujeto. El impulso a la acción en sentido fichteano es una de las caras de una moneda cuyo reverso es aquel sentimiento melancólico. La vida del sujeto peregrino echeverriano $y$

${ }^{9}$ Véase Novalis, NW 2: 334, Nr. 105. Las citas de los textos de Novalis se hacen según la edición completa de 1978: Werke, Tagebücher und Briefe [NW]. marmoliano se ve signada por esta dualidad. ${ }^{10}$ También los conceptos de ideal, refiguración imaginativa [Nachbilden], satisfacción [Befriedigung], aprobación [Beifall] y desaprobación [Misfallen], que Fichte presenta al interior de la dinámica del anhelo, describen tal carácter dual de la subjetividad.

Con esto dicho basta para presentar el objetivo principal del trabajo, a saber: explicar los rasgos y el sentido filosófico del ánimo [Stimmung] del peregrino como figura principal de las obras de Echeverría y de Mármol, en pos de trazar una continuidad respecto de la metafísica del anhelo presente en el pensamiento de Fichte y de Novalis como uno de los máximos exponentes filosóficos de la Frühromantik que, en el presente trabajo, resalta por sobre el resto de los Frühromantiker a la hora de trazar los paralelos respecto de los románticos argentinos.

En este sentido el artículo se estructura en dos partes. En el primer punto se analiza la GWL fichteana. En concreto se estudia la metafísica del anhelo que presenta a partir del séptimo teorema del texto $(\$ 10)$, en que describe esta dinámica como el movimiento fundamental de la subjetividad en la búsqueda de unidad entre sus aspectos finito e infinito. Esta exégesis incorpora también la explicación del concepto de impulso [Trieb] como aparece ya en el cuarto teorema $(\$ 7)$.

\footnotetext{
${ }^{10}$ Echeverría se auto adjudica esta tensión producto de la lógica del anhelo que vincula actividad y melancolía. En sus palabras: "[m]is esperanzas burladas, produjeron en mí una melancolía profunda. Me encerré en mí mismo y de ahí nacieron infinitas producciones". (OCEC V: 450). A su vez Mármol [1846] (1953: 144) caracteriza la voz poética echeverriana como melancólica. Por su parte Sarlo (1997: 31) resume este rompecabezas en el cual se combinan estos caracteres con las palabras: "voluptuosidad de la melancolía".
} 
En el segundo punto se procede con el análisis de las dos obras de los románticos argentinos que se mencionaron. Aunque escritas con veinte años de distancia, $P G$ y $C P$ exponen la Stimmung que se desprende de una concepción filosófica con base en la lógica del anhelo tal como se muestra en el sistema fichteano. En este contexto se destaca el rol metafísico de los conceptos de melancolía, hastío y muerte -tal como lo conciben los románticos franceses y, más importante para el objetivo del trabajo, los alemanes.

Por último, se expone una Conclusión en la que se repasan los argumentos que conforman el trabajo y se destaca la importancia de pensar la subjetividad a partir de la metafísica del anhelo. Ello permite delinear un tipo de existencia humana -peregrina, idealista y romántica-, a partir de la cual se evidencia la importancia de la moralidad y de la libertad como conceptos nucleares a la hora de pensar la subjetividad y su desenvolvimiento en el mundo.

\section{LA METAFÍSICA DEL SEHNEN EN FICHTE}

De acuerdo con el objetivo del trabajo, el texto principal a analizar en esta sección es la GWL fichteana. En concreto los últimos dos teoremas -séptimo y octavo-, en que Fichte se dedica a exponer la metafísica del anhelo. Si bien no se estudian en profundidad los teoremas previos, se precisa remitir a ellos de manera breve, para una adecuada comprensión del desarrollo argumental. De manera específica se llama la atención sobre la noción de tendencia [Streben] (véase Fichte GA I/2: 397), la cual se tiene que considerar en conexión con los principios fundamentales de su sistema, a saber: el yo, el no-yo y la mutua relación entre ambos (véase Fichte GA I/2: 255-272).

De modo sucinto se puede decir que Fichte denomina "tendencia": el carácter de la subjetividad en tanto principio absoluto -yo absoluto. El sujeto no puede dejar de tender hacia la superación del choque [Ansto $\beta$ ] que la realidad le impone en tanto situado en el mundo de lo finito. Ello implica la búsqueda de sí mismo como unidad que abarque todo lo que se le presenta como oposición -no-yo. Sin embargo, en tanto la tendencia no puede más que, en efecto, tender, no se puede realizar por completo. En otras palabras, la tendencia subjetiva hacia lo infinito no consigue producir la realidad nada más que a partir de sí misma. Pero por ser un continuo movimiento en pos de semejante telos, sí la puede superar a partir de su constante modificación. ${ }^{11}$

Con esto dicho y en pos de comprender el rol del anhelo en su sistema filosófico, se impone la necesidad de dar cuenta de qué entiende por el concepto de impulso -que abarca, para su adecuada comprensión, la noción de tendencia. En continuidad con lo que se mencionó con antelación, él agrega que la tendencia no puede producir de modo causal lo que proyecta. Fichte escribe:

[1]a tendencia intenta la causalidad [...]. Pero esta causalidad no puede ser puesta como dirigida hacia el no-yo; pues entonces se pondría no una tendencia, sino una actividad real influyente; sólo podría, pues, revertir sobre sí misma [...]. Pero una tendencia que se produce a sí misma y que es fija, determinada [...] se llama un «impulso». (Fichte, GA I/2: 418).

De esta forma Fichte explicita la diferencia entre los conceptos de tendencia y de impulso. Este último no es más que la tendencia en su determinación a la modificación de la realidad -aunque no a su producción de manera causal. En su tendencia a la unidad el yo proyecta

${ }^{11}$ Las referencias al texto de Fichte se hacen a partir de la edición de la Bayerischen Akademie der Wissenschaften [GA]. 
su total realización en el mundo. Sin embargo, este proyecto siempre queda trunco.

En el marco de un idealismo que no se puede considerar como absoluto, para Fichte la realidad impone una limitación constante a la proyección ideal del yo en cuanto actividad que tiende a colmar lo infinito. Esta limitación hace surgir en él un sentimiento [Gefühl]. ${ }^{12}$ Pero el sentimiento, como tal, tiene que ser siempre determinado. Es decir, el choque por el cual nace el sentimiento tiene que ser la confrontación entre una actividad determinada del yo y una determinada limitación.

En este sentido el yo reflexiona y toma conciencia de sí como tendiente y limitado a la vez. En otras palabras, toma conciencia de sí como impulsado a la modificación de una realidad que lo limita. ${ }^{13}$ Así pues Fichte explica que el impulso no intenta una actividad nada más que ideal sino real. A partir del impulso el yo se determina a la producción de una realidad efectiva fuera de sí. ${ }^{14}$

Pero para mantener el equilibrio en la síntesis de yo y no-yo -y que su sistema filosófico no recaiga en contradicción al afirmar que el yo se puede desenvolver de manera absoluta por sobre la realidad-, Fichte vuelve a señalar que esta actividad del yo no puede realizar un

\footnotetext{
${ }^{12}$ Véase Fichte, GA I/2: 419.

${ }^{13}$ Cruz Cruz (1975: 141, n. 1) explica esta cuestión con las siguientes palabras: "[c]uando Streben se hace consciente, se llama Trieb, «impulso». Trieb [...] es la forma fundamental de mediación práctica entre el yo y el no-yo [...]”. A su vez, dice Villacañas (2001: 98): "[1]a única diferencia entre estas dimensiones reside en la diferencia entre lo indeterminado y lo determinado [...]. Un esfuerzo [(Streben)] determinado y limitado por un choque determinado sentido es una inclinación [(Trieb)]. Esta es esfuerzo limitado".

${ }^{14}$ Véase Fichte, GA I/2: 430
}

objeto determinado. Con respecto a la actividad del yo como impulso dice:

\begin{abstract}
esta actividad del yo se dirige hacia un objeto, el cual no puede ser «realizado» como cosa por el yo [...]. Se trata, pues, de una actividad que «no tiene objeto alguno, pero que no obstante se dirige impulsada irresistiblemente hacia un objeto» [...]. Una determinación tal en el yo se llama un «anhelo» [Sehnen]; un impulso hacia algo [...] desconocido, que sólo se manifiesta por una «necesidad», por un «malestar», por un «vacío» que intenta llenarse y que no indica a partir de qué. El yo siente en sí un anhelo; él se siente menesteroso. (Fichte, GA $\mathrm{I} / 2: 431$ )
\end{abstract}

A continuación, Fichte da un nombre al objeto del anhelo. Es decir, a aquello que el yo produciría a partir del impulso si no encontrara un límite, a saber: el ideal. ${ }^{15} \mathrm{~A}$ su vez señala que el ideal como tal no es aquello que el yo podrá en efecto poner (setzen).$^{16}$ En este sentido subraya un conflicto del yo consigo mismo en tanto limitado e ilimitado, finito e infinito. ${ }^{17}$ En las últimas páginas de la $G W L$ intenta suprimir (heben) esta contradicción. Pero la cuestión a pensar aquí es: ¿hasta qué punto la llega a conciliar?

${ }^{15}$ Cabe mencionar aquí que él afirma: "este anhelo es el vehículo de todas las leyes prácticas” (Fichte, GA I/2: 432/151). En otros términos, en cuanto búsqueda de lo absoluto, el anhelo es el medio para el desarrollo de la ley práctica-moral tal como Fichte hereda tal concepto de la filosofía de Kant. Baste recordar en este punto el impacto filosófico que la lectura de la Kritik der praktischen Vernunft (1788) causó en él -(véase Fichte, GA III/1: 167 y 171). Aquella afirmación es importante ya que en el presente artículo se sostiene que los románticos alemanes y argentinos también heredan el carácter práctico y moral del criticismo kantiano.

${ }^{16}$ En sus palabras: "el anhelo intenta hacer efectivo algo fuera del yo. Esto es lo que él no puede hacer [...]. [E]l objeto del anhelo no tiene ninguna realidad, pero debe tenerla en virtud del anhelo, pues este intenta la realidad" (Fichte, GA I/2: 432 y 434).

${ }^{17}$ Véase Fichte, GA I/2: 432. 
El yo no puede poner con efectividad absoluta el objeto del anhelo. Empero tiene que poner algo efectivo en tanto mediante el anhelo intenta la posición de la realidad. Fichte sostiene que lo que se pone a través del anhelo no es un producto absoluto del yo. En la reciprocación de yo y no-yo - del sentimiento de anhelo y del sentimiento de limitación-, el yo tiende a la determinación de la realidad. Por ende, tiene que haber una realidad material determinable con antelación al impulso del yo que la intenta determinar.

Como conclusión de este razonamiento, afirma: "el impulso que se manifiesta en el yo no intenta "la materia» en general, sino cierta «determinación de la materia» [...]. El anhelo no intenta [...] la producción de la materia, como tal, sino la modificación de esta" (Fichte, GA I/2: 434). Aquí cabe detenerse en el tipo de modificación que el yo produce en el objeto mediante el impulso anhelante. Fichte hace hincapié en este punto en la diferencia entre la determinación [Bestimmung] y la determinabilidad [Bestimmbarkeit] en la relación entre yo y no-yo. Así pues, señala que no se trata de una determinación real $[\text { realiter }]^{18}$ sino de su refiguración imaginativa [Nachbilden].

Entonces no se trata de una modificación del no-yo en sí, sino para el yo. ${ }^{19} \mathrm{~A}$ través del impulso el yo modifica o determina la realidad. Pero la determina de manera imaginaria a partir de su determinabilidad y no como una determinación real y absoluta. ${ }^{20}$ La cuestión para Fichte es descubrir dónde se da esta conciliación entre actividad ideal e impulso a la realidad.

\footnotetext{
${ }^{18}$ También Rivera de Rosales (2014: 220) destaca la importancia de esta cuestión al interior del pensamiento fichteano de la GWL.

${ }^{19}$ Para Fichte: "el impulso de determinación no intenta una modificación real, sino solamente la determinación ideal [...], la refiguración imaginativa [...]. [N]ada queda aquí para una actividad real del yo" (Fichte, GA I/2: 438).

${ }^{20}$ Véase Fichte, GA I/2: 360.
}

Pero de acuerdo con su argumentación, el lugar en que la conciliación se da ya fue descrito, a saber: en el anhelo. El yo oscila mediante el ejercicio de la imaginación entre la proyección de un objeto ideal y la realidad que se muestra distinta respecto de este objeto. Entonces oscila entre la limitación sentida en un punto real y determinado y la intuición que percibe algo que es otro con respecto a esta realidad. Ahora bien, dice Fichte: "[l]a intuición «ve», pero está «vacía»; el sentimiento «se relaciona» con la «realidad», pero es «ciego»" (Fichte, GA I/2: 443).

Sin embargo, en tanto el objeto anhelado es algo diferente de la realidad existente, ambos -idealidad y realidad, objeto del anhelo y objeto real- se concilian -hasta donde es posible- en su reciprocación mutua mediante el anhelo. En sus palabras:

\begin{abstract}
[e]n el anhelo están íntimamente conciliados la idealidad y el impulso a la realidad. El anhelo se dirige a «algo otro»; esto es posible solamente si se presupone una determinación previa por la actividad ideal. Además, el impulso a la realidad (como limitado) se da también en el anhelo, porque esto es «sentido», pero no pensado o representado [...]. Lo anhelado queda ahora determinado; pero únicamente lo es por el predicado de que debe ser «algo distinto» para el sentimiento. (Fichte, GA I/2: 444-445)
\end{abstract}

La pregunta que aquí cabe hacer es: ¿qué tipo de sentimiento experimenta el sujeto a partir de esta síntesis que se da en el anhelo? Es decir: ¿el sujeto se siente a sí mismo como una unidad acabada en que su aspecto finito e infinito se sintetizan de modo total a través de su conciliación con la realidad mundana? ¿ $\mathrm{O}$ acaso no puede experimentar la susodicha unidad? 
Fichte denomina sentimiento de satisfacción al sentimiento en que de forma necesaria tiene que desembocar el anhelo. ${ }^{21}$ En este sentido afirma que no es posible poner un anhelo sin su pretendida satisfacción -de otra forma no se erigiría como tal. Ahora bien, la satisfacción del anhelo implica la desaprobación de aquello a lo cual se dirigió con anterioridad.

Como explica Fichte, en el anhelo se concilian idealidad y realidad. Pero no se puede concebir una identificación última en que el sujeto experimente una armonía total entre lo ideal y lo real, lo infinito y lo finito. El impulso volcado en acción que intenta la realidad, una vez que se satisface, hace surgir un sentimiento de aprobación. Pero esta aprobación conlleva la desaprobación respecto de algo otro que fue objeto de un anhelo previo. ${ }^{22}$

Con respecto a la posición real del objeto que se proyecta de modo ideal en el anhelo, se da una determinación perenne hacia lo infinito. Así pues, el sujeto experimenta una constante aprobación y desaprobación que se da a un tiempo. En este sentido, el sujeto no se experimenta a sí mismo como una unidad armónica. En palabras de Fichte: "[1]a armonía existe, y surge un sentimiento de «aprobación» [...], de acabamiento total (pero que sólo dura un momento, puesto que el anhelo vuelve necesariamente)" (Fichte, GA I/2: 450-451).

\footnotetext{
${ }^{21}$ Véase Fichte, GA I/2: 448/164.

${ }^{22}$ Con relación a esto otro, dice: "este se hace insípido, banal" (Fichte, GA I/2: 448/164). De esta manera se anticipa el rol que el concepto de tedio o hastío tiene en el pensamiento romántico alemán, francés y argentino. En particular Novalis remite a ello en diversos fragmentos. Véase Novalis, NW 2: 475, Nr. 17; NW 2: 276, Nr. 111; NW 2: 676, Nr. 862; NW 2: 777, Nr. 195; NW 2: 835, Nr. 401. Y véase Novalis 1976 : 254. Nr. 1018.
}

Si bien no hay ninguna acción que satisfaga por completo el impulso del yo a la producción de la realidad a partir de su idealidad originaria, el sujeto no puede más que continuar por este camino que a cada momento produce aprobación y desaprobación. En cada acción por la cual el sujeto modifica el mundo, es decir, en cada acción por la cual idealiza, infinitiza, moraliza -y, de acuerdo con la teoría novaliana, romantiza- lo finito, surge un sentimiento de aprobación y un avance en pos de la unidad y de lo infinito.

La falta de satisfacción absoluta no implica que el movimiento del anhelo sea un movimiento nada más que de pérdida. En cada acción el sujeto se gana y se pierde a sí mismo y al mundo. En esto radica el verdadero y único progreso posible para él. ${ }^{23}$ Por este motivo es que cabe considerar al idealismo fichteano de la $G W L$ con base en la metafísica del anhelo como un idealismo práctico-moral y a la vez melancólico.

Los pensadores románticos tanto alemanes, como franceses y argentinos enfatizaron el sentido de semejante punto estructural de la subjetividad. La melancolía como sentimiento del sujeto que expresa la falta de unidad absoluta entre lo finito y lo infinito, fue el punto central de sus cavilaciones. La siguiente sección se dedica a estudiar cómo Echeverría y Mármol presentan esta cuestión a través de la figura del peregrino, como personaje principal -y alter ego- en sus

\footnotetext{
${ }^{23}$ Para preludiar la siguiente sección del trabajo, cabe tomar unas palabras de Echeverría que ilustran la dinámica de ganancia y de pérdida. Escribe en Clasicismo y romanticismo: "marcha el hombre y se robustece; adquieren sazón sus potencias con el ejercicio y poco a poco va realizando las leyes de su ser. En vano [...] calamidades quieren poner a raya y sofocar el instintivo impulso que lo lleva: ceja el hombre un momento; mas se recobra luego, lucha, arrolla los obstáculos, triunfa y sigue adelante. Así, obrando incesantemente, la humanidad progresa [...]" (Echeverría, OCEC V: 108).
} 
obras poéticas. ${ }^{24}$ De esta manera se argumenta en pos de resaltar la influencia del idealismo fichteano y del romanticismo alemán en sus desarrollos intelectuales.

\section{LA METAFÍ́SICA DEL ANHELO EN ECHEVERRÍA Y EN MÁRMOI}

El objetivo en esta sección es poner de manifiesto el sentido del concepto de anhelo en las obras de Echeverría y de Mármol, en continuidad con su presentación según la GWL fichteana. Ahora bien, para que esta argumentación cobre valor hay que mencionar la importancia que aquellos autores adjudican a la noción de libertad. Y ello tanto a nivel político como, más importante aún en el contexto de este artículo, a nivel metafísico. ${ }^{25}$

En efecto, a través del personaje del peregrino exponen la búsqueda metafísica de una realización plena de la libertad del yo sobre el mundo que se puede poner en paralelo con el desarrollo sistemático fichteano acerca de la cuestión. Esta búsqueda adopta el carácter filosófico, literario y biográfico de un viaje a través del mar, en cuanto medio ambiente falto de fronteras y analogía de lo infinito.

\footnotetext{
${ }^{24}$ Echeverría plantea su conexión personal con este personaje -además de en $P G$-, en "El pensamiento", "Lara o la partida" y "El poeta enfermo", por nombrar algunos poemas que componen sus Consuelos (1833-1834). En el caso de Mármol cabe referenciar en particular al Canto quinto de $C P$.

${ }^{25}$ De cualquier manera, tanto en el caso de Echeverría como de Mármol, sus alusiones a la libertad política se encuentran ligadas a la idea del desenvolvimiento de la perfectibilidad y de la racionalidad humana como cuestión de corte metafísico y, en concreto, filosófico moral (véase Echeverría, OCEC III: 123 ss. Véase Mármol [1846] 1953: 293-294). También esto se presenta en la poesía que titula "Desencanto". Aquí liga el afán de libertad política para la incipiente nación Argentina con el ansia de lo infinito -mediante la noción de "paraíso"-, a nivel metafísico. Reza el comienzo del poema: "Mi sueño de oro / en noche ingrata, / ¡ay! fue del Plata / la libertad; / y de mis ansias / el paraíso, / ¡ay! fue el hechizo / de la beldad”(Mármol [1846] 1953: 131).
}

Echeverría y Mármol reapropian el sentido con el que los románticos alemanes y franceses conceptualizan el mar en tanto enclave de lo infinito en la naturaleza mundana. De esta manera homologan la figura del peregrino a la del navegante. A su vez, al viaje que realizan hay que ligar -como se hizo al estudiar la metafísica fichteana-, el sentimiento de hastío y de melancolía de quien sabe que su meta es incognoscible e inalcanzable. ${ }^{26}$

Pero, como para Fichte, la conciencia y el sentimiento melancólico del imposible alcance de lo absoluto no implica, en la comprensión de aquellos autores, el cese de la actividad como impulso hacia ello. ${ }^{27}$ En $P G$, Echeverría describe la Stimmung del personaje principal en tono melancólico y da cuenta de su experiencia acerca de: "los desengaños del mundo y [de] lo efímeras que son las ilusiones y los placeres" (Echeverría, OCEC V: 4-5), y del reproche que sufre acerca de su falta de acción.

Y más adelante escribe: “Gualpo se había cansado rápido de todas las cosas del mundo y aun de la esperanza” (Echeverría, OCEC V: 11). Ya en este punto se evidencia la conexión del pensamiento echeverriano con la lógica del anhelo fichteana. En particular en lo que remite al carácter pasajero del placer o contento [Zufriedenheit] que el sujeto puede alcanzar, que siempre da paso a la renovación del ansia.

${ }^{26}$ En Clasicismo y romanticismo Echeverría manifiesta de modo explícito la conexión entre estas figuras poéticas y el intelectual romántico atravesado por tales sentimientos. Así dice: "el romántico, reflexivo y melancólico, [...] va [...] en busca, como el peregrino, de una tierra desconocida" (Echeverría, OCEC V: 97).

${ }^{27}$ También en Clasicismo y romanticismo escribe acerca de los románticos: "los de imaginación sombría como su destino, que insaciable y no satisfecha, busca siempre perfecciones ideales y aspira a ver realizadas las esperanzas que su creencia le infunde" (Echeverría, OCEC: V: 96). 
También se puede leer como ejemplo de la dinámica del anhelo, el siguiente comentario que escribe Echeverría acerca del peregrino: "[s]in embargo, un pequeño lampo de esperanza aun lo sustentaba [...]. [A] un la tierra no estaba desierta para él y [...] el mundo encerraba algo que pudiese procurarle algunas satisfacciones [...]" (Echeverría, OCEC V: 12).

Ahora bien -una vez más en continuidad con cómo lo pensó Fichtecabe decir que la actividad esperanzada que desenvuelve el peregrino no implica el anhelo de nada objetivo. Escribe Echeverría en la última estrofa de su poema Al corazón (1835): “[n]o te pido ¡oh Dios! riqueza,/ felicidad, poderío/ gloria, deleites, grandeza;/ manjares que dan hastío,/ y nunca pueden saciar [...]" (Echeverría, OCEC III: 175). ${ }^{28}$ Así pues, tal como reza el epígrafe de Fichte que encabeza el trabajo, el anhelo no indica a partir de qué cosa se puede llenar. Más aun, de acuerdo con la lógica propia de este movimiento, no la hay.

En todo caso, la actividad esperanzada de tal sujeto es una actividad lanzada a la modificación o romantización del mundo en un perpetuo movimiento de superación de la realidad y de sí mismo en pos de lo absoluto o incondicionado [das Unbedingte], es decir, de acuerdo con la terminología de los idealistas y románticos alemanes, en pos de lo no cósico.

\footnotetext{
${ }^{28}$ Cabe resaltar aquí la aparición del hastío como carácter inherente a la dinámica del anhelo. A su vez en Himno al dolor (1834) Echeverría explicita que el hastío es una de las caras de la moneda que surge junto con la esperanza del impulso anhelante. Dice allí: “¿[q]ué esperanza me has dejado,/ qué idea no has sofocado/ en mi espíritu al nacer? / ¿Qué pasión o sentimiento / no me has trocado en tormento? / ¿Qué amor o contentamiento / en hastío o displacer?" (OCEC III: 167). Por su parte, Sili (1944: 14-15) destaca el tedio y el hastío como signo personal del carácter de Echeverría.
}

Echeverría remite aquí a Kant como trasfondo filosófico de la construcción de lo que en su poemario es: el alma peregrina. ${ }^{29} \mathrm{Y}$, de acuerdo con el paralelo que se trazó entre el idealismo moral kantiano y fichteano, también hay que poner en sincronía el alma del peregrino con el yo como principio del sistema de la GWL. Es decir, el peregrino echeverriano y el sujeto fichteano no anhelan más que la consecución de la ley moral -de raíz kantiana-, en cuanto mandato a la constante autosuperación que se erige por encima de toda objetividad y ley mundana.

Dice Echeverría, en su Himno al dolor, acerca del alma peregrina que califica como arrogante y noble en este constante impulso hacia lo incondicionado:

¿[q]ué aflicción o desventura / podrá parecerme dura? [...] / ¿Qué placer del mundo activo / puede tener atractivo / para mi pesar esquivo? / ¿Qué llenar mi alma podrá? [...] / [V]erás que una alma arrogante [...] / siempre brilla flamante / sin admitir mancha en sí [...] / [Q]ue una alma noble [...] / es contra la adversidad; / como el Océano sublime / que de ley común se exime [...] (Echeverría, OCEC III: 168 y 170).

De esta manera Echeverría da cuenta de la fuerza peregrina para continuar desenvolviendo su actividad en el mundo finito como práctica moral, que no es otra cosa que aquella libertad como cuestión clave del pensamiento que los románticos argentinos heredan del idealismo alemán. Así lo afirma el alter ego echeverriano: "ya mi barca se entrega a merced de los vientos y [...] las ondas voraces. Bastante

${ }^{29}$ Véase Echeverría, OCEC III: 170. 
luché ya con los elementos de mi infausto destino, y ahora nueva lucha emprendo, pero no tan terrible" (Echeverría, OCEC V: 6). ${ }^{30}$

Ahora bien, aquí surge un problema que puede atentar contra el desarrollo de la hipótesis del trabajo. De acuerdo con la última cita, el medio marítimo promueve un desarrollo de la subjetividad en su búsqueda por lo infinito que resulta mejor -o en cualquier caso, menos terrible-, que la vida en la tierra, como mundo de lo finito.

Entonces hay que preguntar: ¿acaso el mar, en tanto medio falto de fronteras, habilita ya la total superación del aspecto finito de la vida subjetiva? ¿El anhelo y la melancolía que surgen en el medio oceánico, son vías para una redención acabada de lo finito y un consuelo de la existencia? De ser así habría que asociar estos caracteres a un pensamiento religioso y no se podría situar a Echeverría en continuidad con el idealismo moral que Fichte presenta en la GWL.

En términos más generales se trata de una cuestión que, como tópico romántico, también aparece en Mármol, a saber: el desencanto del sujeto con respecto al mundo y lo que este tiene para ofrecer, de modo tal que aquél pretende retirarse de dicho ámbito. Y para continuar con los interrogantes que enmarcan el desarrollo argumental: ¿qué significa que el sujeto, en particular el peregrino romántico, anhele su retiro del mundo? ¿Supone ello un afán suicida? ¿Implica el cese de su actividad práctica?

\footnotetext{
${ }^{30}$ En este tono escribe en Al corazón: “[m]as yo continúo luchando / con un genio incontrastable, / con mi corazón, sudando, / al destino irrevocable / obedezco a mi pesar; / y no puedo en mi ansia fiera / ni una lágrima siquiera / para alivio derramar" (Echeverría, OCEC, III: 174).
}

En este punto cabe resaltar que estas preguntas tienen como trasfondo histórico y filosófico el planteo de dicho tema por parte de los Frühromantiker, en particular por parte de Novalis. ${ }^{31}$ A partir de la lectura de sus fragmentos y de sus obras literarias y poéticas, se impone la necesidad de responder la pregunta respecto de qué conlleva la falta de sentido del mundo de lo finito con relación al anhelo subjetivo. Asimismo, al leer el conjunto de la obra novaliana, también surge la pregunta acerca de la clase de pensamiento idealista y romántico que desarrolla. Es decir, si se trata de un idealismo moral en la estela de la GWL o bien de un pensamiento de carácter religioso.

Para responder estas preguntas -y a la vez que en el marco de la herencia fichteana se pone en evidencia la conexión del romanticismo de Echeverría y de Mármol con el de Novalis-, cabe adentrarse en el concepto de muerte y de suicidio, que van de la mano con la idea de un retiro del mundo como aspecto clave de las ideas de estos autores.

Hardenberg dedica diversos fragmentos a este tópico. En Vermischte Bemerkungen (VB) (1797-1798) escribe: “[1]a muerte es una autosuperación - que como todo triunfo sobre uno mismo, proporciona una existencia nueva y más ligera" (Novalis, NW 2: 230: Nr. 11). Y en otro: "[1]a vida es el inicio de la muerte. La vida existe a causa de la muerte. La muerte es principio y final a la vez - separación y unión más íntima con uno mismo a la vez" (Novalis, NW 2: 230, Nr. 15). Finalmente se refiere al suicidio, también de modo engalanado, como: "el verdadero acto filosófico" (Novalis, NW 2: 223, Nr. 20).

\footnotetext{
${ }^{31}$ A su vez, a partir del influjo del romanticismo alemán, también los franceses asumieron este planteo. Musset escribe en La confession d'un enfant du siècle: "[c]uando las ideas [...] alemanas pasaron [...] sobre nosotros, produjeron un abatimiento [...]. Fue aquello como una negación de todo lo del cielo y de la tierra, que se puede llamar desencanto" (Musset [1836] 1944: 10).
} 
Según estos pasajes, la motivación que lleva al sujeto a la muerte no implica el anhelo de encontrar una calma última en que cese su actividad. En todo caso se trata de la reafirmación de la metafísica fichteana que supone que semejante estado es imposible de alcanzar, y enaltece la actividad moral de constante superación de la realidad y auto superación, como única y más alta posibilidad para el desarrollo de la subjetividad en el mundo y en pos de lo incondicionado.

En este sentido cabe citar de manera conjunta otro par de fragmentos novalianos en que se plantea que el desarraigo que el sujeto romántico sufre respecto del mundo de lo finito, no implica que tenga que morir -o, de ser posible, vivir por fuera del mundo. Dice en una de sus frases de mayor resonancia: “"[b]uscamos» por todas partes lo incondicionado y «encontramos» siempre sólo cosas" (Novalis, NW 2: 226, Nr. 1). ${ }^{32} \mathrm{Y}$ a su vez sostiene en el texto que se editó como Fragmenblatt (1797): "en el mundo se tiene que vivir con el mundo" (Novalis, NW 2: 223, Nr. 21). ${ }^{33}$

Entonces, aun a través de la afirmación de la falta de valor del mundo de lo finito que sólo ofrece cosas, y el consecuente impulso a su abandono en pos de una existencia superior, Novalis no convoca con ello ni a una muerte material ni a la idea de la posibilidad de una redención religiosa -y, como tal, acabada- de la vida subjetiva que sólo puede fluctuar entre lo finito y lo infinito de modo constante.

\footnotetext{
${ }^{32}$ Una idea similar a esta la expone, en el contexto del romanticismo francés, Chateaubriand. Él escribe en su novela René: "[s]ólo busco un bien ignorado [...]. ¿Es mi culpa si encuentro siempre límites, si lo finito no tiene para mí ningún valor?” (Chateaubriand [1802] 1977: 93). A su vez estas palabras reproducen la dinámica del anhelo -cuyo objeto se ignora-, según se grafica en el epígrafe fichteano.

${ }^{33}$ La traducción es propia.
}

Echeverría plantea esta cuestión en los mismos términos. Se pregunta en Al corazón:

¿[q]ué corazón es el mio? [...] / ¿Cómo cabe entre mi pecho, / cuando su vuelo atrevido / halla el universo estrecho, desprecia lo conseguido, / y sin cesar pide más? / ¿Cómo [...] anhela / se roe a sí mismo, y vela / sin fatigarse jamás [...]? / Parece que el hombre errante, / como triste peregrino / marcha con pie vacilante, / sin saber por qué camino, / en pos de alguna visión; / de paso echa una mirada / sin arraigar aquí a nada / su voluble corazón. (Echeverría, OCEC III: $171 \mathrm{ss})^{34}$

El peregrino echeverriano, en su tendencia al vuelo como elevación por sobre el mundo de lo finito, no consigue satisfacer su ansia a través de ninguna cosa. De esta manera, la dinámica del anhelo se extiende de modo perpetuo. Pero ello no invita a la idea de una muerte material ni a una creencia religiosa en la posibilidad de alcanzar un punto último de reposo. En efecto, tal como expresa Echeverría, el corazón peregrino no se fatiga jamás.

Así también la descripción de la vida del sujeto a bordo de un navío como ámbito superior al mundo de lo finito no conlleva, para este autor, la idea de un enclave en que se sublime la tensión entre los aspectos finito e infinito de la subjetividad. En efecto, en sus términos poéticos, el peregrino o el navegante nunca alcanza de manera definitiva un puerto en el cual encontrar una calma tal que el impulso hacia lo absoluto se detenga.

\footnotetext{
${ }^{34}$ La cuestión del peregrinar melancólico como carácter de vida aparece también en una de las Rimas echeverrianas de mayor renombre: La cautiva. Sobre este texto escribe Llorente Medina (1984: 60): "recorre el poema un sentimiento de nostalgia, que contempla la vida del hombre como un triste y continuo peregrinaje".
} 
De esta manera escribe, contra la idea de la posibilidad de un olvido y alejamiento total del mundo, ${ }^{35}$ que el consuelo que Gualpo experimenta en alta mar no conlleva una cicatrización de "las llagas de su corazón" (Echeverría, OCEC V: 12) que surgen, en lenguaje filosófico, de la falta de satisfacción total del anhelo. Así también describe el movimiento del navío -con el cual el peregrino experimenta una simbiosis-, como una constante elevación hacia el cielo -en cuanto imagen de lo infinito- y caída en el abismo:

las olas empujadas más y más por los vientos forman ya montañas que se elevan al cielo, levantando en sus hombros inmensos al pino endeble que se desploma de allí y cae en las profundidades del abismo, y se levanta de nuevo después de haber desaparecido". (Echeverría, OCEC V: 15) ${ }^{36}$

La lógica del anhelo y la experiencia del desencanto con respecto al mundo y el afán por su superación se presentan también en el pensamiento y la lírica poética de Mármol. Tal como en el caso de Echeverría, el sujeto romántico toma la figura del peregrino y del

\footnotetext{
${ }^{35}$ Esta idea se desliza pocas páginas antes de que aparezcan las palabras que se citan a continuación en el cuerpo del texto. Véase Echeverría, OCEC V: 10-11.

${ }^{36}$ Echeverría también esboza esta dinámica de satisfacción e insatisfacción del impulso hacia lo absoluto en diversos poemas que componen sus Consuelos. Por ejemplo en "Contestación”, escribe: "[a]llí anhela calmar su sed ardiente [...] / Y con alas de fuego divagando / el infinito abarca y remontando / más y más se sublima [...] / Pero vano delirio, mi destino es batallar con el dolor continuo [...]" (Echeverría, OCEC III: 47 ss.). Y en “Adiós” -una vez más a través de las imágenes marítimas-, dice: "[n]o quiere tierna amiga / la fortuna enemiga / puerto a mi vela dar, / y en frágil barca nueva / peregrino me lleva / por borrascoso mar [...] / donde en ausencia larga, / a mi tristeza amarga / consuelo no hallaré" (OCEC III: 60-61). Por ultimo menciona en "Layda": "[m]i alma sucumbe con el grave peso / del infortunio, y en la tierra no halla / mi corazón, para aliviar su herida, / bálsamo dulce [...]. / Doquiera miran mis cansados ojos / duelo tan sólo y confusión encuentran, / y nada, nada, que mis ansias pueda / calmar un tanto" (OCEC, III: 151).
}

navegante. A su vez el mar aparece como el medio ambiente de privilegio para el desenvolvimiento de su existencia.

Entonces hay que analizar si la descripción marmoliana de la vida peregrina en el mar, reporta la idea de una posible superación absoluta del aspecto finito de la existencia subjetiva. Más aun, ello se impone como una necesidad en tanto Mármol remite de manera explícita al carácter religioso del sentimiento melancólico que surge en el océano. Si se determina que su pensamiento acerca de esta cuestión adopta semejantes rasgos, entonces no se podría trazar el paralelo respecto del idealismo moral fichteano. ${ }^{37}$

En el espíritu del romanticismo novaliano, Mármol remite al desencanto con relación a lo finito como rasgo inherente a la existencia peregrina. Escribe hacia el final del canto segundo en $C P$ : “yo [...] llevo el desencanto / fijo, entrañado en la vida, / como el dolor en la herida, / como en la llama el calor" (Mármol [1846] 1953: 41). ${ }^{38}$ De

\footnotetext{
${ }^{37}$ Aquí cabe enfatizar que la imposibilidad de trazar este paralelo remite, tal como se explicitó, al sentido moral del idealismo fichteano. En otras palabras, se trata de la dificultad de conciliar la GWL con un pensamiento de corte religioso, según el cual la relación finito-infinito puede alcanzar una unidad final. Si bien es cierto que obras posteriores de Fichte dan lugar a esta idea, y que incluso los Frühromantiker desarrollaron teorías religiosas tanto a partir de ellas como, hasta cierto punto, a partir de la $G W L$, es necesario distinguir el espíritu de este texto respecto de doctrinas religiosas para poder apreciar su justo valor, así como su importancia en el marco de la comparación con respecto a otras versiones de la $W L$. En este caso resulta útil valerse del análisis que, algunos años después de la última edición de la $W L$, hizo Schopenhauer sobre Fichte. En sus palabras: "[Fichte] se había atrevido a prescindir de las doctrinas de la religión nacional en su filosofar [...]. [T]ras su posterior nombramiento en Berlín, el yo absoluto se había convertido obedientemente en el amado Dios y toda su teoría en general cobró una apariencia [...] cristiana [...]" (Schopenhauer [1851] 2009: 169).

${ }^{38}$ También se refiere a ello en el poema que titula "Crepúsculo" -al interior del quinto canto (véase Mármol 1953: 130)-, y más adelante en el poema “A Emilia”
} 
allí que, también en continuidad con la dinámica romántica del anhelo presente en Novalis y en Echeverría, Mármol exprese su impulso a la destrucción de todo lo finito en pos de una existencia superadora en lo infinito: "[y]o soy un hombre que tranquilo rompo / desde que niño fui cuanto he querido [...] / después mi corazón en mil pedazos, / y del mundo después todos los lazos" (Mármol [1846] 1953: 98).

A su vez de la mano con el rol de la noción de desencanto aparece la conceptualización de la melancolía y del hastío. ${ }^{39}$ En el canto segundo asocia el ansia o la aspiración hacia algo que aparece como lejano, con el hastío que sufre el alma que se impulsa en esta dirección. En un tono en el que resuena el modo en que Fichte da cuenta del sentido del anhelo en GWL, escribe Mármol de modo poético acerca de Carlos -su alter ego en $\mathrm{CP}$-:

ese Carlos, insondable foco / de perpetua inquietud y de constancia $[\ldots]$ / se recrea / en desechar la idea / que antes buscaba el corazón con ansia: / alma que vive en perdurable hastío [...] / que al lado del calor percibe frío, / y en medio del placer inventa penas; / que vuela, busca, ve, toca, delira; / y cuando está en su mano / la posesión de a lo que inquieto aspira, / por algo más lejano / su veleidoso corazón suspira. (Mármol [1846] 1953: $33-34)^{40}$

(véase Mármol 1953: 140). Por último en el canto doceavo (véase Mármol [1846] 1953: 241).

${ }^{39}$ Mármol ([1846] 1953: 139) se auto adjudica este carácter a través de su alter ego. ${ }^{40}$ Cabe destacar cómo a través de la remisión conjunta a las imágenes del calor y del frío y al placer y las penas, Mármol grafica el carácter siempre dual del anhelo melancólico de lo absoluto -tal como también se desprende de la filosofía fichteana. En el canto undécimo aparecen una vez más aunados el placer y el cansancio o, en los términos que se utilizaron hasta aquí, el hastío (véase Mármol [1846] 1953: 223).
Ahora bien, de la misma manera que sucede al leer a Echeverría, el estudio de la obra de Mármol puede conllevar la idea que él concibió que la existencia de carácter hastiante y melancólico se puede superar por completo. Así se redimiría el movimiento del anhelo. En este punto su pensamiento adopta un carácter religioso ajeno al idealismo y al romanticismo de carácter moral según se describió en la obra de Fichte y en los fragmentos de Novalis.

Como en el poema echeverriano, Mármol remite al mar como el ambiente en que el aspecto religioso de la melancolía favorece un estado de calma y de consuelo para el peregrino-navegante. En sus palabras:

[t]odo era triste, religioso, dulce; / es la hora en el mar que más nos habla / en mudo melancólico lenguaje, / el idioma benéfico del alma [...]. / Hora en que el navegante retraído [...], / tiene fijos los ojos en el cielo / y conversa tranquilo con el alma [...]. / Las horas indecisas de la tarde / en que la naturaleza arrodillada / ruega al Dios [...], y en dulces, melancólicos suspiros / parece que en el éter se derraman / sus místicas plegarias, difundiendo / paz y consolación para las almas, / sólo el amor y religión inspiran, / sólo el amor y religión nos hablan. (Mármol [1846] 1953: 112 ss.)

También en el marco de la herencia del romanticismo alemán en los intelectuales argentinos, es importante resaltar la asociación marmoliana entre la religiosidad melancólica del mar con el rol que desempeña la conceptualización del amor como vía de redención de la existencia finita. ${ }^{41}$ En este sentido no es aleatorio que Mármol homologue la hora en el mar con la hora de amar. ${ }^{42}$ La mujer amada aparece

${ }^{41}$ Por su parte Novalis conceptualiza el amor como figura de lo absoluto en particular en sus obras literarias Die Lehrlinge zu Saïs (1798) y Heinrich von Ofterdingen (1799-1800).

${ }^{42}$ Véase Mármol [1846] (1953: 113). 
en el poema como figura de lo absoluto -de forma paralela con Dios y la patria. ${ }^{43}$ De esta manera el sentimiento amoroso que se experimenta en el medio marítimo favorecería una religazón que, por fuera del mundo, unifique los aspectos finito e infinito de la subjetividad y sublime la dinámica del anhelo. En continuidad con ello, Mármol escribe:

[y]a está sobre los mares [...]. / Ya puede -desprendidos sus lazos con el mundo- / volar a los espacios su espíritu hasta Dios [...]. / Y el mundo desaparece [...]. / [Y] solamente vagan los ojos en un prisma/ de eternidad y calma, felicidad y amor. / Al viajador errante joh mar! de tu desierto / sin que lo sepa su alma, le sirve de crisol, / y ante la fe se inclina, purificado [...]. / El hombre, ese rebelde proscrito sobre el mundo, / que aun no ha reconciliado la sangre de la Cruz, / se sublimiza, si ama, y en nuevo ser fecundo / se torna a las regiones de su primera luz. (Mármol [1846] 1953: 190-191)

Empero, más allá de las alusiones a tal estado de unidad, el tono de los cantos marmolianos conlleva enfatizar que el sentido romántico de su pensamiento implica la idea de la imposibilidad que el anhelo se sublime y el sujeto pueda abandonar por completo la existencia finita. En efecto, Mármol insiste sobre esta cuestión aun cuando describe la sublimidad del mar, de Dios, de la amada y de la patria: "todo es grande en el mar, todo sublime [...]. / Lo individual se olvida o desvanece". Pero luego escribe: “[t]an sólo el corazón desciende al mundo / -al mundo del recuerdo y de las ansias- / y tierno y melancólico suspira / por su Dios, por su amor y por su patria” (Mármol [1846] 1953: 116).

${ }^{43}$ Véase Mármol [1846] (1953: 116).
Con estas palabras acentúa la idea que sólo desde el mundo de lo finito puede el sujeto relacionarse con lo absoluto. Esta relación se configura a través de un impulso que no es más que el anhelo de una existencia superior en que el sujeto se desenvuelva por completo sobre el mundo y se alcance a sí mismo como unidad. Pero dicho movimiento superatorio no consigue abrir las puertas de un paraíso -tal como la lírica marmoliana expresa el concepto de lo infinito-, que permanece cerrado. ${ }^{44}$

Entonces la actividad peregrina es una actividad moral. Es, aun en el mar como ámbito superior para el desarrollo de su existencia, naufragio y lucha. ${ }^{45}$ Es decir, carencia de un enclave firme en el cual alcanzar una calma redentora y perpetuación de la dinámica del anhelo en pos de un absoluto siempre lejano. Por este motivo la actividad peregrina es también una actividad melancólica, en tanto todo objeto del mundo de lo finito causa hastío y nunca puede poner punto final al movimiento.

La profundidad y la multiplicidad de ocasiones en que los románticos argentinos remiten a la experiencia del desencanto como propia de la estructura de la subjetividad de sus personajes peregrinos en quienes se reflejan, conlleva pensar que desarrollaron su pensamiento filosófico y poético en la línea idealista y romántica de Fichte y de Novalis. Es decir, en continuidad con un pensamiento de corte moral con base en la metafísica del anhelo.

${ }^{44}$ Escribe acerca del peregrino de sus cantos: "osa volar [...], como un ángel sin alas sollozando / junto a las puertas del Edén cerradas” (Mármol [1846] 1953: 116-118). ${ }^{45}$ Dice Mármol acerca del derrotero de la nave en que viaja el peregrino: "surca [...] en el mar de las pasiones / naufragando y luchando sin cesar" (Mármol [1846] 1953: 189). 


\section{CONCLUSIÓN}

A lo largo del trabajo se desarrolló el objetivo propuesto, a saber: dar cuenta del sentido que la figura del peregrino adopta en $P G$ de Echeverría y en $C P$ de Mármol. De esta manera se evidenciaron las ideas no sólo literarias sino filosóficas de uno y otro en torno a la cuestión de la conformación metafísica de la subjetividad. En particular se explicitó el carácter dual de la Stimmung subjetiva, que se desprende de la estructura trascendental del personaje y alter-ego de los autores. Es decir, se mostró cómo se relacionan el hastío, la melancolía y el desencanto respecto del mundo, con el impulso a la constante actividad en pos de la superación de las trabas que encuentra.

Ahora bien, esta explicación se realizó a partir de la continua remisión al sistema filosófico idealista de Fichte y también con relación al pensamiento romántico de Novalis. En efecto, uno de los puntos clave del trabajo fue mostrar por qué medios y de qué forma sus ideas atravesaron el pensamiento echeverriano y marmoliano. Más aun, el artículo puso de manifiesto que los tópicos y los desarrollos del idealismo y del romanticismo alemán, no se pueden dejar de considerar a la hora de pensar las influencias que tuvieron los intelectuales argentinos de la primera mitad del siglo XIX -a través del rol que, en este contexto, cumplió el romanticismo francés.

En concordancia con la hipótesis que se esbozó, al analizar las obras de Echeverría y de Mármol se encuentran alusiones implícitas y explícitas a Kant, Fichte y los Frühromantiker. Estas conexiones se tienen que englobar en el contexto del desarrollo de un pensamiento y de un proyecto filosófico de corte moral y, en particular, con base en la metafísica del anhelo como punto de partida no sólo del pensamiento sino de la acción del sujeto en el mundo.
Es cierto que los románticos argentinos tuvieron mayor acceso a las obras de los románticos franceses que a textos de los idealistas y los primeros románticos alemanes. Empero, esta situación no conllevó que sus ideas no se enraizaran en estos autores. Más aun, el curso literario y filosófico francés de la primera mitad del siglo XIX debió, en gran medida, su conformación al idealismo y al romanticismo alemán. Por ende, no se puede ignorar o negar el rol de estos filósofos en los argentinos.

Ya en lo que remite no tanto a la cuestión formal e histórica sino al contenido propio de la filosofía que heredaron, se resaltó que el modo en que Fichte describió la dinámica del anhelo en GWL conlleva la idea de la imposibilidad que el sujeto se conozca, intuya o experimente a sí mismo como una unidad acabada finito-infinito. De hecho, el concepto mismo de anhelo en conjunción con los conceptos de tendencia e impulso, son las claves para la conformación de un idealismo que, si bien piensa lo absoluto o lo incondicionado, no supone que puede dar cuenta de ello más que como un telos práctico al que se orienta la actividad subjetiva.

De acuerdo con Fichte, el sujeto siempre se encuentra a sí mismo lanzado hacia lo infinito en tanto superación absoluta del choque que el mundo le impone. En otras palabras, se encuentra a sí mismo impulsado hacia un objeto ideal que, como tal, no se puede crear ni presentificar en el mundo de lo finito. En efecto, para Fichte el sujeto no puede llevar a cabo una creación absoluta. De lo que se trata en el marco del movimiento anhelante es de la modificación o romantización continua del mundo en pos de un objetivo que se sabe inalcanzable -a través de la combinación de la proyección subjetiva ideal y de su actividad material. 
Es por este motivo que Fichte afirma, tal como rezan las palabras del epígrafe, que el sujeto siempre se siente menesteroso [bedürftig]. En otros términos, al igual que lo concibió Novalis, el sujeto se mueve siempre entre el hastío y la melancolía ante la imposible satisfacción absoluta del anhelo, y la actividad incesante que lo impulsa en su búsqueda.

Ahora bien, a partir de esto último el pensamiento fichteano no derivó en una concepción mecánica de la subjetividad. El impulso no es una fuerza mecánica que la sobrepasa. Por el contrario, es justo en la tensión propia de semejante dinámica, que la libertad se muestra como carácter inherente al sujeto. En este sentido, en el contexto de la metafísica fichteana -y también novaliana-, ser libre implica ganar y perder al mundo y a sí mismo en y con cada acción.

A raíz de estas ideas, el idealismo de la GWL y el modo en que Novalis lo asumió -a partir de algunos de sus fragmentos que se citaron-, dan lugar a calificar su filosofía como una filosofía crítica y prácticamoral. Crítica en tanto -al igual que lo pensó Kant-, no conforma un sistema que supone que puede dar cuenta de una unidad total finitoinfinito. $\mathrm{Y}$ práctica-moral en tanto expone la existencia subjetiva como una actividad que se desenvuelve de manera oscilante entre lo finito y lo infinito sin nunca alcanzar una religazón total. Religazón imposible en tanto el yo absoluto, como principio del sistema, ya se encuentra atravesado por aquella tensión.

Por otra parte $-\mathrm{y}$, hasta cierto punto, de manera justificada según algunos pasajes de las obras de todos los autores que se trataron-, en ocasiones se leyó el idealismo y el romanticismo como corrientes de pensamiento religioso. Es decir, sistemas o ideas según los cuales sería posible para el sujeto alcanzar -sea en el mundo o por fuera de él-, una unidad final de su existencia. En el presente trabajo se analizó esta cuestión tanto a partir del sistema de la GWL como en su proyección en Novalis y en el romanticismo argentino.

Pero incluso a partir de pasajes de los textos de Echeverría y de Mármol según los cuales se puede esgrimir aquella lectura, se concluyó que ambos autores se alinearon con la metafísica del idealismo moral fichteano así como con su continuación en el romanticismo novaliano. En particular se enfatizó que aun las alusiones a la religiosidad de la melancolía -que asoma de modo concreto en la naturaleza marítima-, no conllevan pensar que los románticos argentinos concibieron la existencia subjetiva de modo religioso.

Tendencia, impulso, anhelo, melancolía y hastío son conceptos que en el marco del idealismo y del romanticismo -tanto alemán como francés y argentino-, dan cuenta de la estructura metafísica del sujeto según la cual este se desenvuelve de manera libre en el mundo. Su libertad reside justo en la medida en que no se puede desarrollar de manera plena sobre todo aquello que se le opone como parte de lo finito. Así pues, la libertad peregrina del sujeto idealista y romántico reside en la constante superación de la realidad y de sí mismo que encuentra su motor en el anhelo de lo que no es ni puede llegar a ser.

\section{REFERENCIAS}

ARRIETA, Rafael Alberto (1953), “Prólogo”, en Mármol ([1846] 1953: VII-LIV). Chateaubriand, François-René [1802] (1977), Atala. René. El último Abencerraje, trad. de Manuel Altolaguirre (Madrid: Espasa-Calpe). CRUz CrUZ, Juan (1975), “Introducción”, en Fichte (1975: IX-LVII).

ECHEVERRÍA, Esteban (1870-1874), Obras completas de Esteban Echeverría [OCEC] (Buenos Aires: Carlos Casavalle Editor).

(1944), Clasicismo y romanticismo (Buenos Aires: Sophos). 
(1984), Rimas, ed. preparada por Antonio Lorente Medina (Madrid: Editora Nacional, DL).

FICHTE, Johann Gottlieb (1962), J. G. Fichte-Gesamtausgabe der Bayerischen Akademie der Wissenschaften [GA] (1962), hrsg. von Reinhard Lauth (Stuttgart-Bad Cannstatt: Frommann-Holzboog).

_ (1975), Doctrina de la ciencia, trad. de Juan Cruz Cruz (Buenos Aires: Aguilar).

Goldman, Noemí (ed.) (2005), Nueva historia argentina, tomo III: Revolución, república, confederación (Buenos Aires: Sudamericana).

HooG, Armand (1954), "Who invented the Mal du Siècle?", Yale French Studies, 13: 42-51.

JITRIK, Noé (1979), “El romanticismo. Esteban Echeverría”, en Zanetti \& Delgado (1980-1986: 241-264).

KRUMPEL, Heinz (1999), Die deutsche Philosophie in Mexiko: ein Beitrag zur interkulturellen Verständigung seit Alexander von Humboldt (Berna: Peter Lang).

LlORENTE MEDINA, Antonio (1984), “Introducción”, en Echeverría (1984: 9-73).

LOTUFO, Marcelo Freddi (2017), Romanticism in Brazil and Argentina (Rhode Island: (c) by Marcelo Freddi Lotufo).

MÁrmol, José [1846] (1953), Cantos del peregrino, (Buenos Aires: Ediciones Estrada).

MUSSET, Louis-Charles-Alfred [1836] (1944), La confesión de un hijo del siglo, trad. de Ricardo Gil (Buenos Aires: Editorial Sopena).

MYERS, Jorge (2005), “La revolución en las ideas: la Generación romántica de 1837 en la cultura y en la política argentinas", en Goldman (2005: 381-445).

Novalis (1948), Los fragmentos, seguidos de Los discípulos en Sais, trad. de Mauricio Maeterlinck (Buenos Aires: Editorial El Ateneo).

(1978), Werke, Tagebücher und Briefe [NW], hrsg. von Hans-Joachim Mähl und Richard Samuel, 3 Bde. (München-Wien: Carl Hanser Verlag).
(2007), Estudios sobre Fichte y otros escritos, trad. de Robert CanerLiese (Madrid: Akal).

ORTIZ, Tulio (2007), "El pensamiento político de Echeverría”, Revista electrónica del Instituto de investigaciones "Ambrosio L. Gioja”, 1: 134155.

PoviñA, Alfredo (1955), “Esteban Echeverría Precursor de la Sociología Argentina”, Revista Mexicana de Sociología, 17, 2/3: 561-579.

RIVERA DE ROSALES, Jacinto (2014), “The Methodical Singularity of the First Fichte”, en Rockmore (2014: 211-230).

ROCKMORE, Tom (ed.) (2014), Fichte and Transcendental Philosophy (New York: Palgrave Macmillan).

SARLO, Beatriz (1997), "El poeta" en Sarlo \& Altamirano (1997: 17-47).

SARlo, Beatriz \& Altamirano, Carlos (1997), Ensayos argentinos. De Sarmiento a la vanguardia (Buenos Aires: Ariel).

SCHOPENHAUER, Arthur [1851] (2009), Parerga y Paralipómena I, trad. de Pilar López de Santa María (Madrid: Trotta).

SILI, Eros Nicola (1944), "Prólogo”, en Echeverría (1944: 7-33).

STAËL, Mme. de [1810] (1852), De l'Allemagne (Paris: Libraire de Firmin Didot Fréres).

SuÁREZ URTUbEY, Pola, "Esteban Echeverría, precursor del pensamiento musical argentino", Revista del Instituto de Investigación Musicológica "Carlos Vega", 8: 65-97.

VILLACAÑAS BERLANGA, José Luis (2001), La filosofía del Idealismo alemán. Vol. I (Madrid: Editorial Síntesis).

ZANETTI, Susana \& DELGAdo, Josefina (eds.) (1980-1986), Historia de la literatura argentina (Buenos Aires : Centro Editor de América Latina). 